\title{
DÚVIDAS, ERROS, SURPRESAS, IMPLICAÇÕES: ENTREVista COM PhilipPe LejeUne
}

\author{
Ana Amelia Coelho, Claudia Amigo Pino, \\ Josias Padilha, Mario Tommaso, \\ Mônica Gama, Samira Murad
}

Tradução de Carolina Augusto Messias, Mario Tommaso e Ana Amelia Coelho Apresentação de Ana Amelia Coelho

\section{Apresentação}

Philippe Lejeune desenvolve, desde a publicação de seu primeiro livro, L'autobiographie en France, em 1971, um trabalho em torno da expressão autobiográfica em suas mais variadas formas.

Em paralelo ao trabalho de professor na Universidade Paris-Nord, em Villetaneuse, Lejeune escreveu ensaios teóricos e análises tratando da autobiografia como manifestação artística. Para tanto, centrou-se num conceito: o "pacto autobiográfico", ato enunciativo que possibilita ao leitor fazer a distinção entre uma narrativa ficcional e um relato de vida.

Ao longo de seu trabalho, Lejeune deslocou os limites de seu estudo da expressão autobiográfica: as questões teóricas que fundamentam a noção de pacto foram colocadas em discussão, motivada por críticas de outros autores. Além disso, as análises passaram a ter como objeto não somente obras literárias, mas as diversas manifestações da experiência pessoal: diários, autorretratos, relatos radiofônicos, documentários, entrevistas televisivas, blogs... inclusive o seu próprio texto crítico tornouse objeto de análise.

Nesse percurso, Lejeune passou do trabalho acadêmico à "militância" em favor dos escritos pessoais. Há mais ou menos 20 anos, em parceria com Chantal Chaveyriat-Dumoulin, fundou a Associação pela autobiografia e o patrimônio autobiográfico (APA). Sediada em Ambérieu-en-Bugey, na França, acolhe escritos pessoais de todo e qualquer interessado - iniciativa que abriu um espaço de diálogo até então difícil de ser colocado em prática. Seu site, Autopacte, reúne textos de sua autoria, informações sobre eventos bibliografias sobre autobiografia e temas conexos.

Apresentações incomodam e provocam. Por mais que se entenda o seu papel, há o receio de que a descrição de uma realidade se torne norma e, repetida, impeça que vozes dissonantes se levantem.

Esta entrevista se coloca numa posição irresoluta. Quer apresentar Philippe Lejeune e, ao mesmo tempo, juntar-se aos seus textos e aos estudos que dialogam com suas ideias. Ainda assim, apresentar trazendo informações diferentes das que já circulam - e que algumas vezes cedem à força da repetição. 
Nesse gesto de escrúpulo, evitando contribuir na construção monolítica da figura do entrevistado, a simples reiteração do que já se sabe a seu respeito, preferiu-se tomar caminhos pouco explorados. A entrevista foi construída como um trabalho coletivo. Nas perguntas dirigidas a Lejeune, temos vozes de diferentes tons, que, num esforço comum, deixaram vir à tona "dúvidas, erros, surpresas e implicações”. Mais ou menos próximas do trabalho em torno da autobiografia, aceitaram o desafio de jogar no espaço entre a cerimônia e a familiaridade - espaço esse que é também, acreditamos, aquele que nosso entrevistado nos abre.

\section{Entrevista}

Seria possível identificar um caráter próprio à expressão de si no interior das literaturas nacionais? Por exemplo: na literatura brasileira há poucos autobiógrafos; por outro lado, nossos escritores se dedicaram mais à correspondência e ao diário.

O senhor já falou em alguns textos sobre certa relação entre o gênero autobiográfico e a civilização ocidental... Podemos observar que uma parte considerável de seu trabalho está concentrada no domínio francês. Qual a razão dessa escolha? Em que a autobiografia se relaciona a questões particularmente francesas? Que relações constrói com outros campos além do francófono?

Simplesmente, o francês é a única língua que eu domino (mais ou menos!). Eu falo, compreendo e escrevo em inglês no dia a dia, mas não o suficiente para assimilar e dominar as culturas anglófonas. E não conheço outra língua. Quando comecei meu trabalho, não havia nenhuma história da autobiografia na França. Refleti sobre a definição do gênero, fiz inventários, li e explorei bastante, e elaborei um primeiro painel (L'autobiographie en France, 1971). E, desde então, trabalhei sobre o domínio francófono tanto em relação ao diário quanto à autobiografia; é um campo imenso, o suficiente para preencher uma vida de pesquisador. Isto é válido para a maioria dos países e culturas - e para o Brasil, em particular! O primeiro trabalho a fazer é explorar sua própria cultura. Todas as culturas, é claro, têm a sua especificidade. Mas vocês têm certeza de que existam assim tão poucos autobiógrafos no Brasil? Vocês fizeram inventários completos, procuraram nos arquivos? Não são apenas os escritores que escrevem suas vidas! E mais: que limites vocês estabelecem para o que denominam "autobiografia"? Existe uma História da autobiografia no Brasil?

Admito conhecer mal as culturas estrangeiras, mas nunca tive a pretensão de tratar da Autobiografia no mundo ou da Autobiografia no Ocidente. Constato, aliás, que quase todo o mundo está na mesma situação que eu. Somos limitados por nossas competências linguísticas e pela raridade das traduções. É preciso, portanto, ser prudente, descrever o que conhecemos e não apresentar como universal o que é local. Raros são os livros que realmente abarcam várias culturas. Houve, em alemão, os livros de Georg Misch, em francês, os de Georges Gusdorf. Os estudos comparatistas são raríssimos: conheço poucos além dos de Richard N. Coe, que compara narrativas de infância lidas no texto original em seis línguas diferentes (alemão, inglês, espanhol, francês, italiano, russo). Podemos facilmente confrontar culturas autobiográficas, graças a trabalhos coletivos, como a muito útil Encyclopedia of life 
writing (2001, 2 volumes) coordenada por Margaretta Jolly (acabo justamente de ler o artigo "Brasil", escrito por um inglês!).

No entanto, os gestos metodológicos circulam de uma cultura a outra. Os dois capítulos teóricos do Pacte autobiographique ("Le pacte autobiographique" e "Autobiographie et histoire littéraire") propõem um método analítico, inspirado na linguística, e uma reflexão sobre a história dos gêneros que podem, espero, transpor as fronteiras... e mesmo os oceanos.

Nas últimas décadas, assistimos a mudanças consideráveis nos limites entre o privado e o público. O íntimo infiltra no espaço público, renovando as noções de intimidade. Nesse sentido, poderíamos dizer que a superexposição da intimidade fez com que o gênero autobiográfico perdesse força e por essa razão se fragmentasse?

Perder força? Pelo contrário! Nunca a quantidade da produção autobiográfica parece ter sido tão grande e (ao menos na França) é um lugar-comum condená-la (a autobiografia vista frequentemente como má literatura). Mas a qualidade literária parece não ter sofrido com isso: o que se chama na França de “autoficção", palavra inventada em 1977 por Serge Doubrovsky, é ao mesmo tempo uma produção experimental (que permite testar os procedimentos de estilo ou de construção mais livres) e transgressiva (que põe em cena mais indiscretamente a vida privada - a do autor e a de seus próximos!). É certo que, há uma ou duas gerações, os discursos públicos sobre a vida privada e, em particular, a vida amorosa, tornaram-se mais livres no espaço das mídias (televisão e Internet). Mas se, por um lado, os limites se deslocam, por outro, eles não desaparecem, e as pessoas, em sua vida privada, não estão nem mais felizes, nem menos solitárias: elas simplesmente dispõem de alguns meios a mais para falar disso. É preciso ver as coisas também na longa duração: a cada geração, desde o século XIX, tivemos a impressão de que o íntimo estava, como nunca, em praça pública (em geral, para dizermos que ele era excessivo e perigoso!). Mas a verdade é que desde os anos 1960 o ritmo de mudança dos meios de comunicação se acelerou, e muito mais coisas e pessoas tornaram-se visíveis; por outro lado, criou-se na Internet o que chamei de "intimidades de rede" (com a possibilidade de entrar como ator, em um nível microscópico, no turbilhão da comunicação). É verdade, portanto, que nós estamos num momento de rápida mudança. Mas não se deve manter um discurso de lamentação ("superexposição", "perder força", "fragmentar"), como se as formas anteriores da intimidade fossem naturais e melhores. O eu não é algo estável que se "exprimiria" de um modo mais ou menos completo conforme os meios de comunicação: o próprio eu é produzido e modelado pelos meios de comunicação.

A partir de nossas experiências como estudantes e pesquisadores estrangeiros na França, observamos que as instituições de pesquisa se organizam em grupos fechados e bastante especializados. No entanto, há universidades que trabalham em novos modelos, com cursos mais abertos à participação do estudante. 
Acredita que seu trabalho como professor universitário e crítico literário contribuiu para modificar a relação entre professores e estudantes? No que diz respeito à redação de teses, por exemplo, a abordagem dos pósgraduandos é mais subjetiva que antes? Como os professores e orientadores acolhem os textos mais pessoais?

Devo confessar uma coisa: no sistema francês, eu nunca pedi o título de "professor". Fiquei afastado da orientação de teses; não orientei, portanto, nem fiz parte de nenhuma banca. Eu tinha guardado uma péssima lembrança do caráter formal que ainda tinha a instituição universitária nos anos 1960 e mesmo 1970 - aliás, eu mesmo não fiz tese, sentia-me incapaz disso. Então, eu desenvolvi minhas pesquisas livremente, publicando-as aos poucos, e dialoguei pessoalmente com os estudantes e pesquisadores que tinham vontade de me consultar a respeito do meu trabalho. Mas eu sou um mau exemplo, que não deve ser seguido. O sistema francês atual está nitidamente melhor, e as relações diretas e pessoais entre professores e pós-graduandos são bem mais frequentes. Vocês me perguntam se a abordagem dos pós-graduandos é mais subjetiva do que antes... Como eu quase não leio teses, é difícil de responder! Mas por que uma tese deveria ser "subjetiva" - é esse o adjetivo que melhor convém? Uma tese deve produzir um saber partilhável. Eu diria que ela deve ser "pessoal" - em dois sentidos: na invenção e na exposição. Quanto à invenção, é preciso ter a coragem de explorar novos domínios, ou de tentar novos métodos (quantas teses, por prudência, tratam de assuntos “batidos”!). Quanto à exposição, é preciso ter o escrúpulo de integrar, discretamente, a própria história da pesquisa (dúvidas, erros, surpresas, implicações) para melhor validar os resultados. Uma tese não é uma efusão, mas um aprendizado do trabalho científico, que tem a ganhar se for conduzida de maneira inventiva e controlada. É por isso que, quando se redige uma tese, vale muito a pena escrever um diário!

É visível que seus textos críticos se desviam de uma certa linguagem teórica que poderíamos esperar dos estudos literários. A primeira pessoa do plural, utilizada em L'autobiographie en France, deu lugar ao "eu". Assumiu nos seus textos, ao longo do tempo, o direito à mudança, e até mesmo à contradição, contando "fábulas teóricas".

Percebe esse tipo de desvio em outros textos críticos?

A crítica literária é também uma atividade de escritor? Ou, ao contrário, ela é um exercício do fracasso?

Demorei muito tempo antes de me arriscar, nos meus escritos públicos, a fazer um discurso pessoal. Eu sentia um duplo perigo: o de chatear ou aborrecer o leitor, e o de expor minha intimidade de um modo imprudente. Desde os 15 anos de idade, pratico diferentes formas de escritura íntima, diários ou textos pessoais, destinados somente a mim. Não é uma questão de fracasso ou sucesso: é algo que faço apenas para acompanhar minha vida. Eu não sou escritor. Exerço, como todo mundo, o ofício de viver, e por isso escrevo. Eu amo a escritura. Eu me sinto melhor depois. E tento escrever melhor, isto é, de forma clara e verdadeira. Minha história é a de uma aproximação gradual entre minha prática de escritura íntima e minhas produções profissionais. Eu havia escolhido ser professor de literatura, mas levou tempo para que eu compreendesse que as minhas pesquisas podiam tratar daquilo que, por outro 
lado, era a minha paixão. Eu tinha 31 anos, em 1969, quando decidi fazer uma ponte entre as duas metades da minha vida e estudar a autobiografia. E esperei ainda muito tempo antes de dar espaço a um discurso pessoal nas minhas publicações sobre a autobiografia. Isso começou com meu livro sobre Michel Leiris, em 1975, e sobretudo com seu "Post-scriptum", publicado em 1986 no livro Moi aussi. Mas eu ainda era tímido: em meu livro-investigação sobre a prática do diário (“Cher cahier...”, 1990), não incorporei meu próprio depoimento aos dos 47 autores de diário que me haviam feito confidências. Foi só um pouco mais tarde, trabalhando com os diários de moças do século XIX (Le moi des demoiselles, 1993), que me veio a ideia de publicar meu diário no lugar do livro clássico que me dava tédio de escrever. Eu não aconselharia a ninguém imitar minha preguiça! Eu recorri uma segunda vez ao diário em 1999-2000, quando eu passei um ano a observar o que acontecia na Internet (“Cher écran...”, 2000). A partir dessa época, eu parei, para que isso não se transformasse num método: poderia ser cansativo. Há outras formas de ser pessoal no tom e no percurso e de, ao se envolver, envolver o leitor... É preciso saber dosar o eu, evitar o excesso, senão, como um bolo muito açucarado, corre-se o risco de ser enjoativo...

Nós, do grupo Criação \& Crítica, trabalhamos juntos numa revista eletrônica, com o objetivo de guardar a memória de nossos trabalhos e também participar do debate em torno da criação e da crítica em literatura.

O senhor faz parte da comissão editorial de Poétique, na editora Seuil, revista na qual publicou alguns artigos, notadamente seu texto mais conhecido, O pacto autobiográfico. É também o responsável pela publicação de La faute à Rousseau, revista da Associação pela autobiografia e pelo patrimônio autobiográfico (APA). No que tange ao seu trabalho de leitura e escrita, quais as principais diferenças entre as duas publicações? Em que medida o contexto e o suporte de publicação interferem no seu trabalho?

Poétique? É uma velha (e bela) história... que começou nos anos 1970. Depois da publicação do Pacto, Gérard Genette e Tzvetan Todorov me recrutaram para fazer parte do Conselho de redação. Esse Conselho, pelo que eu sei, nunca se reuniu pessoalmente: tudo acontecia pelo correio. Recebíamos artigos para avaliar de tempos em tempos. Nós também podíamos submeter nossos próprios artigos para serem avaliados, ou tomar iniciativas. Fiz isso duas ou três vezes. Por exemplo, coordenei, com meu amigo Jean Verrier, um número dedicado ao ensino da poética nos liceus ( $\mathrm{n}^{\circ}$ 30, abril de 1977). Ou, mais recentemente ( $\mathrm{n}^{\circ} 149$, fevereiro de 2007), sugeri uma reunião de artigos em torno das "Fronteiras da autobiografia”. Sou muito grato a Genette e Todorov por me terem feito participar dessa bela aventura, e a Michel Charles, que atualmente dirige a revista.

La faute à Rousseau? É uma história... bastante atual. O comitê de redação se reúne seis vezes por ano (duas vezes para cada número; há três números: em fevereiro, junho e outubro), sempre na casa de um de nós (somos em torno de dez), e cada reunião termina com um jantar alegre e com muita bebida. A revista partiu... do nada: em outubro de 1992, o primeiro número possuía 24 páginas fotocopiadas. Atualmente, produzimos de 80 a 84 páginas em quatro cores, e a revista, com tiragem de 900 exemplares, é enviada a todos os membros da Association pour l'autobiographie (são quase 700 membros). 
Os artigos são curtos, devem ser claros e atraentes. Cada número traz um dossiê temático (em 2010: fevereiro, "Fotografias"; junho, "O esquecimento"; outubro: "A Europa e a autobiografia”) e crônicas da atualidade, apresentações de livros, etc. É um tipo de revista de cultura geral, para o "grande público", para pessoas comuns que se interessam por autobiografia. O trabalho de nosso pequeno grupo é de propor esses artigos, de encomendá-los, de escrever alguns, de corrigi-los e de organizá-los. Sou o responsável pela coordenação e pela diagramação. Cada número traz cerca de cinquenta artigos, e deve chegar a tempo à caixa de correio dos associados. É emocionante fazer, à vezes um pouco estressante (na hora do "fechamento"). Nós encomendamos artigos, mas também recebemos propostas espontâneas, e assim revista é escrita, de uma certa maneira, por seu público. Eu mesmo escrevo artigos frequentemente (além dos editoriais, das apresentações, etc.), e acho apaixonante escrever numa forma breve: saber, por exemplo, que temos 2000 toques, e não mais do que isso, para ir direto ao essencial e suscitar interesse no leitor. Em suma, é uma forma de jornalismo cultural.

Poétique e La faute à Rousseau estão nos dois extremos de minha atividade "editorial", um foi o ponto de partida "erudito", o outro, o ponto de chegada "popular". Mas entre os dois, eu tive outras aventuras editoriais, outras formas de trabalho em grupo, mais clássicas, fundadas no convívio com grupos de pesquisa. De 1985 a 1999, eu promovi um grupo de trabalho, "Narrativas de vida", na Universidade de Nanterre, onde eu aprendi a organizar e a publicar colóquios. Em 1995, fundei um grupo de pesquisa sobre "Gênese e autobiografia" no ITEM (CNRS) [Instituto de Textos e Manuscritos Modernos do Centro Nacional de Pesquisa Científica], dirigido por Catherine Viollet, que organiza seus seminários, jornadas de estudos, publicações: nosso seminário mensal termina sempre com um bom almoço.

No momento em que muda de objeto, passando das autobiografias aos escritos pessoais, pode-se dizer que, de alguma maneira, o senhor abandona os escritores? Ou que deixa de produzir um certo tipo de crítica? Como vê o seu trabalho? Considera-se hoje um teórico, um professor, um crítico, um historiador, um leitor...?

Abandonar os escritores? Nunca! Mas tratar menos deles, talvez. Trabalhei apenas com os escritores que me pareciam trazer formas de revolução na escritura autobiográfica - Rousseau, entre os do passado; Leiris, Sartre, Perec, Sarraute, Claude Mauriac, entre os contemporâneos. Eu construí meu pequeno Panteon de pioneiros. E, em relação à maioria deles, adorei estudar a gênese de suas invenções, trabalhar com seus rascunhos. Mas tive um pouco de medo de me tornar "especialista" de um autor. Eu sempre desejei mudar e me movimentar - permanecendo fiel às minhas admirações. A verdade é que, há mais ou menos quinze anos, eu passei a trabalhar bem menos com escritores. Há duas razões para isso. A primeira é meu interesse crescente e militante pelas chamadas "escritas ordinárias", das quais poucas pessoas realmente se ocupam (não me preocupo com os escritores, há muita gente em torno deles!). A segunda é o meu - talvez estranho! — desinteresse pela direção na qual descambou uma parte da criação literária atual na França, e pelos debates que ela suscita: a chamada autoficção. 
Como eu vejo o meu trabalho? Como um canteiro em movimento, que se amplia progressivamente em círculos concêntricos, ao redor de um núcleo. Eu passei da autobiografia literária à autobiografia comum e depois ao diário, que é a forma mais democrática e difundida da escritura pessoal.

Como me considero hoje?

Teórico: sim. Desde "Le pacte autobiographique" e de "Autobiographie et histoire littéraire" (1975) até "Le journal comme antifiction" (2007), eu analisei apaixonadamente os mecanismos, e devo muito a Gérard Genette, em particular.

Professor? Em princípio, não sou mais — aposentei-me em 2004 — mas espero ainda ser um (frequentemente faço intervenções em bibliotecas, salas de aula, etc. - e, claro, em colóquios). Gosto de partilhar e explicar. Gosto de ler em voz alta e contar histórias. Ensinei durante 34 anos na mesma universidade, uma universidade de periferia (Villetaneuse, Paris-Nord), quase exclusivamente para iniciantes. Lá, organizei uma disciplina optativa intitulada "A autobiografia hoje", cujo assunto era... o que ia se passar (no plano da expressão autobiográfica) ao longo do ano que começava, e sugeria exercícios de escritura ou trabalhos práticos (por exemplo, em história oral, registrar a história de vida de um avô).

Crítico? Sim, evidentemente, fui um crítico, quando tratei de "grandes escritores", e continuo sendo quando escrevo, em La Faute à Rosseau, sobre os livros mais variados.

Historiador? Acredito que sim. A autobiografia é um campo de estudo interdisciplinar: um mesmo objeto pode ser visto de maneira muito diferente pelos sociólogos, psicólogos, antropólogos, historiadores, especialistas em ciências da educação, etc. Participei de muitos colóquios de diferentes disciplinas sem nunca pensar que praticava de fato essas disciplinas - exceto em relação à história. Eu reivindico o belo título de historiador por meu estudo sobre os diários de moças do século XIX, e sobretudo por aquele que empreendo, já faz dez anos, sobre as origens da prática do diário na França.

Leitor? Evidentemente, é a base de todas as outras atividades. Mas com a leitura eu tenho uma experiência especial, proporcionada pela Association pour l'Autobiographie. Desde 1992, nós recolhemos, lemos, comentamos, arquivamos todos os textos autobiográficos (relatos, diários, cartas) inéditos que nos são confiados. É uma aventura extraordinária ler os relatos de vida que não são - e nunca serão - livros, que não foram selecionados por ninguém e que não selecionaremos (aceitamos tudo), e entrar em contato com os seus autores.

À palavra "leitor", que vocês me sugerem, acrescentaria um sexto termo: militante.

Acompanhando as atualizações do seu site na Internet, Autopacte, vemos que está trabalhando num projeto de livro que vai tratar das "origens do diário". Há periodicamente novos textos no site. Em que medida expor o processo de criação constitui um tipo de autobiografia?

Sim, é a primeira vez que eu uso a Internet para me autopublicar. Primeiro, faço um resumo do meu projeto. Até agora, os estudos sobre as origens do diário na França no século XVIII eram feitos 
somente a partir de diários publicados. Parecia-me um erro metodológico. Tento repará-lo procurando os diários em questão no lugar em que eles podem estar, caso não tenham sido destruídos: nos arquivos. Encontrei, assim, uma série de diários manuscritos inéditos, alguns absolutamente admiráveis. Meu futuro livro será uma coletânea de monografias, cada apresentação de diário poderá ser lida como um pequeno conto. Como passo meu tempo a explorar arquivos, e a encontrar coisas imprevistas, talvez eu nunca possa colocar um ponto final nessa pesquisa. Então, esperando a publicação em papel, decidi ir colocando gradativamente meu livro no site. Atualmente, há mais ou menos 30 pequenos capítulos programados, dentre os quais 24 já se encontram online, com uma introdução e um sumário. Dessa forma, morrerei tranquilo: será possível publicar postumamente minha sinfonia inacabada.

Neste momento, algumas de suas obras (Je est un autre, Moi aussi, Calicot, La mémoire et l'oblique...) estão esgotadas. Lire Leiris, uma delas, já está disponível integralmente em seu site. Como já disse, em suas investigações e no seu trabalho em curso, privilegia os diários que não foram publicados, os "diários desconhecidos".

Quais são as perspectivas de publicação e de reedição de seus escritos em livro?

De que maneira a Internet permite a difusão do seu trabalho? E por que razões a publicação em papel ainda se faz necessária?

Eu vou contar essa história. Lire Leiris, publicado em 1975 pela editora Klincksieck, esgotado desde o começo dos anos 80, voltou a ser lembrado em 2004, quando $A$ idade viril entrou no programa do concurso de admissão de professores de Letras. Retomei meus direitos sobre o livro e o propus à editora Seuil, que não o quis. Decidi editá-lo no meu site e oferecer a todos os estudantes o acesso gratuito ao meu livro. Do ponto de vista técnico, fui um pouco desajeitado, porque escaneei o livro por inteiro, depois o passei por um programa de reconhecimento de caracteres, recorrigi e coloquei tudo online, em modo texto. Teria sido mais simples colocá-lo em modo imagem, mas eu não sabia fazer isso. Essa será provavelmente a solução para os meus outros livros, pois ninguém nunca mais vai reeditá-los, não é lucrativo. A mesma coisa aconteceu com o meu livro sobre Perec: a editora P.O.L. pensou numa reedição, depois desistiu. Eu sou como vocês, eu prefiro o papel. É claro que a maior parte dos livros tem uma vida limitada. Mas não é preciso se queixar: eles sobrevivem num certo número de bibliotecas públicas ou universitárias, é o essencial. Tanto pela sobrevivência, como pelo prazer da leitura, eu prefiro o papel à Internet. Lemos mal, com dificuldade, na tela - quando se trata de um livro inteiro. E depois, um dia, um grande bug talvez fará a Internet desaparecer. Mesmo assim, adoro meu site: ele realizou meus sonhos de infância. Eu brinco sozinho, faço reparos, ninguém vem me aborrecer. Meu site é pouco frequentado, os visitantes são raros, mas motivados, vindos do mundo todo (vocês são a prova!). Minha filha Alice ilustrou-o com desenhos, transformando "Autopacte" num personagem espero eu simpático, em todo caso, pitoresco. Atualizo quase todo dia minhas diferentes bibliografias, as informações sobre colóquios, etc. É como se eu cuidasse de um pomar. No mundo das mídias clássicas 
(livro, televisão) reina uma concorrência feroz: os vencidos são eliminados e esquecidos. Na Internet, os vencidos sobrevivem. Isso custa uma ninharia, e você não incomoda ninguém. Você pode esperar em paz que um príncipe encantado venha acordar o seu site adormecido.

Acredita que hoje em literatura seja possível fugir à expressão de si? A “verdade" seria um refúgio, que se constrói para se proteger do mundo, a fim de garantir uma certa individualidade? Como não fazer autobiografia em literatura?

Parece que suas questões compreendem duas coisas diferentes. Por um lado, a ideia de que o individualismo contemporâneo seria uma reação de recuo diante da mundialização, a febre das trocas, a mestiçagem ou a perda das identidades. Talvez... Por outro lado, o receio de que a literatura enfraqueça, perca o sentido do universal e da criação (é uma censura que se faz frequentemente à literatura francesa atual, vista como fria e narcisista). É possível, também. Mas eu confesso ter dificuldade em dar respostas globais e simples a questões sobre realidades imensas, tão complicadas. Prefiro, para terminar esta entrevista, ampliar um pouco o horizonte para além do campo da literatura.

Estamos começando a viver, há um meio século, um movimento formidável de expansão da expressão autobiográfica nas diferentes artes da imagem que pareciam, a priori, as menos adaptadas à expressão do eu: em particular, a história em quadrinhos (desde Maus) - hoje, na França, há duas editoras especializadas em histórias em quadrinhos autobiográficas (L'Association e Ego comme X) - e o cinema do autor (o mais distante do cinema de ficção - a obra-prima do cinema autobiográfico na França sendo, provavelmente, O homem-cinema [Le filmeur, 2005], de Alain Cavalier). Tudo se passa como se a autobiografia não fosse um movimento insensível de recuo, mas um impulso de expansão, em que o eu fala ao mesmo tempo de si e do mundo, procurando inventar novas formas. Mesmo o sucesso da palavra "autoficção" (ao menos na França) resulta provavelmente dessa nova boa consciência do eu, que concede a si mesmo o direito à invenção. Na França, até o início do século XX, a autobiografia permaneceu relativamente tímida, na velha-guarda da literatura. Ela parece, neste momento, ocupar a linha de frente, passando do convencional ao experimental.

Por outro lado, para ficar no campo da expressão escrita, não seria necessário ampliar a observação para além da literatura publicada e canônica, ao vasto campo de escrituras "ordinárias", que geralmente não o são tanto assim? O problema é que, por não serem coletadas, elas se perdem muito rápido: a cada falecimento, as famílias jogam fora muitas coisas... O problema também é que elas constituem o objeto de estudos da parte de especialistas que não se comunicam entre si. Os sociólogos, os historiadores, os especialistas de ciência da educação, os literários fazem, cada um, as pequenas tarefas de sua parte. Em cada disciplina, existem redes de trocas internacionais muito intensas (a prova é que vocês me propuseram esta entrevista!). Em compensação, no plano nacional, entre disciplinas, nos aproximamos pelas bordas, ignorando-nos uns aos outros. Os hábitos intelectuais, as preocupações da carreira, tudo se opõe à comunicação, e a uma ação comum para conservar esse grande tesouro que está começando a se perder. Na França, a Association pour l'Autobiographie, ao coletar, fora de qualquer limite disciplinar, 
diários, narrativas e correspondências (já coletamos, lemos e indexamos mais de 2500), tenta criar um terreno para o encontro e o diálogo... e isso não é fácil! Desculpem-me por terminar com esta nota militante...

\section{Algumas publicações de Lejeune}

1971: L'Autobiographie en France

1975: Lire Leiris. Autobiographie et langage

1975: Le Pacte autobiographique

1980: Je est un autre. L'Autobiographie de la littérature aux médias

1984: Calicot

1986: Moi aussi

1990: “Cher cahier...”. Témoignages sur le journal personnel recueillis et présentés par Philippe Lejeune

1991: La Mémoire et l'Oblique. Georges Perec autobiographe

1993: Le Moi des demoiselles. Enquête sur le journal de jeune fille

1998: Les Brouillons de soi

2000: “Cher écran...". Journal personnel, ordinateur, Internet

2005: Signes de vie. Le Pacte autobiographique 2

2007: Le journal comme “antifiction”. Poétique, n 149, février 2007

\section{Publicações em português}

O pacto autobiográfico : de Rousseau à Internet. Organizado por Jovita Maria Gerheim Noronha. Belo Horizonte: UFMG, 2008.

Entrevista com Philippe Lejeune, concedida a Jovita Maria Gerheim Noronha.

Ipotesi, revista de estudos literários. Juiz de Fora, v. 6, n. 2, 2002, p. 21-30.

Disponível em: <http://www.ufff.br/revistaipotesi/files/2009/12/Entrevista-com1.pdf>.

\section{Sites}

Autopacte: <http://www.autopacte.org>

L'Association pour l'autobiographie et le Patrimoine Autobiographique (APA) :

$<$ http://www.sitapa.org>

Referência eletrônica: COELHO, Ana Amelia; GAMA, Mônica; MURAD, Samira; PADILHA, Josias; PINO, Claudia Amigo; TOMMASO, Mario. Dúvidas, erros, surpresas, implicações: Entrevista com Philippe Lejeune. Tradução de Carolina Augusto Messias, Mario Tommaso e Ana Amelia Coelho. Apresentação de Ana Amelia Coelho. Revista Criação \& Crítica, n. 4, p. 197-206, 2010. Disponível em:

<http://www.fflch.usp.br/dlm/criacaoecritica/dmdocuments/16CC_N4_entPLejeunept.pdf> 